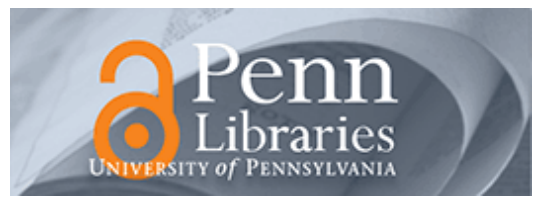

University of Pennsylvania ScholarlyCommons

\title{
The Benefits of Higher Education: Sex, Racial/Ethnic, and Socioeconomic Group Differences
}

Laura W. Perna

University of Pennsylvania, Iperna@gse.upenn.edu

Follow this and additional works at: https://repository.upenn.edu/gse_pubs

Part of the Higher Education Commons, and the Social and Cultural Anthropology Commons

\section{Recommended Citation}

Perna, L. W. (2005). The Benefits of Higher Education: Sex, Racial/Ethnic, and Socioeconomic Group Differences. The Review of Higher Education, 29 (1), 23-52. http://dx.doi.org/10.1353/rhe.2005.0073

This paper is posted at ScholarlyCommons. https://repository.upenn.edu/gse_pubs/371

For more information, please contact repository@pobox.upenn.edu. 


\title{
The Benefits of Higher Education: Sex, Racial/Ethnic, and Socioeconomic Group Differences
}

\author{
Abstract \\ This study analyzes data from the NELS:92/00 to explore sex, racial/ethnic, and socioeconomic group \\ differences in the benefits that high school graduates realize from college. Sex differences in higher \\ education benefits may be a source of observed differences between women and men in college \\ enrollment and degree attainment rates. The findings also suggest that observed racial/ethnic and SES \\ group differences in college enrollment cannot be attributed to actual differences in higher education's \\ economic and non-economic benefits, as some benefits are greater for African Americans than for \\ Whites and benefits generally do not vary by SES. \\ Disciplines \\ Education | Higher Education | Social and Cultural Anthropology
}


The Review of Higher Education

Fall 2005, Volume 29, No. 1, pp. 23-52

Copyright (C) 2005 Association for the Study of Higher Education

All Rights Reserved (ISSN 0162-5748)

\section{The Benefits of Higher Education: Sex, Racial/Ethnic, and Socioeconomic Group Differences}

\section{Laura W. Perna}

College enrollment and degree attainment rates vary by sex, race/ethnicity, and socioeconomic status (SES). While men continue to receive the majority of first-professional (54\%) and doctoral degrees (55\%), women now receive the majority of degrees awarded by colleges and universities nationwide at the associate's (60\%), bachelor's (57\%), and master's (59\%) degree levels (National Center for Education Statistics [NCES], 2003). Among 18to 24-year-old high school graduates, college enrollment rates have been higher for women than for men each year since 1993 (Baum \& Payea, 2004). African Americans and Hispanics are underrepresented among degree recipients at all levels relative to their representation in the eligible population. In 1999-2000 African Americans represented 13\% of all public high school graduates, but only $11 \%$ of associate's degree recipients, $9 \%$ of bachelor's degree recipients, $8 \%$ of master's degree recipients, $7 \%$ of firstprofessional degree recipients, and 5\% of doctoral degree recipients (NCES, 2003). Similarly, Hispanics received $11 \%$ of all public high school diplomas, but only $10 \%$ of associate's degrees, $6 \%$ of bachelor's degrees, $5 \%$ of 
master's degrees, $5 \%$ of first-professional degrees, and 3\% of doctoral degrees (NCES, 2003). Although college enrollment rates have generally been increasing over time for all groups, the approximately 30 percentage point gap in college enrollment between low- and high-income students is comparable in size to the gap that existed in the 1960s (Gladieux \& Swail, 1999). In 1999, 57\% of low-income students enrolled in college, compared with $86 \%$ of high-income students (Gladieux \& Swail, 1999).

An economic model of human capital investment assumes that individuals decide to enroll in higher education and persist to degree completion based on a comparison of the expected benefits and costs of all alternatives (Becker, 1962, 1993; Ellwood \& Kane, 2000; Hossler, Braxton, \& Coopersmith, 1989; Paulsen, 2001). The short-term consumption benefits of attending college include enjoyment of the learning experience, involvement in extracurricular activities, participation in social and cultural events, and enhancement of social status. The long-term investment benefits of higher education include higher lifetime earnings, a more fulfilling work environment, better health, longer life, more informed purchases, and lower probability of unemployment (Baum \& Payea, 2004; Bowen, 1997; Leslie \& Brinkman, 1988). The costs of investing in a college education include the direct costs of attendance (e.g., tuition, fees, room, board, books, and supplies) less financial aid, the opportunity costs of foregone earnings and leisure time, and the costs of traveling between home and the institution (Becker, 1993).

Research shows that enrollment decisions are influenced by the costs of attendance (Heller, 1999; Kane, 1999; St. John, 2003). Specifically, enrollment rates are negatively related to tuition, but positively related to financial aid, especially aid in the form of grants (Kane, 1999; St. John, 2003). Research also shows that sensitivity of enrollment to tuition and financial aid is greater among African Americans and individuals with lower family incomes than for other students (Heller, 1997).

With regard to benefits, researchers (Becker, 1993; Ellwood \& Kane, 2000) note that trends in college enrollment generally mirror trends in the college earnings premium (i.e., the gap in earnings between college and high school graduates). Nonetheless, although a rational human capital investment model assumes that individuals consider both monetary and nonmonetary benefits, little is known about the ways in which benefits other than earnings influence college enrollment decisions.

Little is also known about variations in the relationship between educational attainment and particular benefits across groups. Although some researchers have explored variations by gender in the return to education in terms of salaries (Cooper \& Cohn, 1997; Perna, 2003), little is known about differences by gender or across racial/ethnic and SES groups in the range of economic and noneconomic benefits that human capital theorists (e.g., 
Becker, 1993; Paulsen, 2001) assume result from additional education and are considered in a rational model of college-enrollment decision-making.

This study begins to address part of this knowledge gap by using descriptive and multivariate analyses to explore sex, racial/ethnic, and socioeconomic group differences in several economic and non-economic benefits that 1992 high school graduates realize from higher education by 2000, eight years after leaving high school. Supporting earlier conclusions (Becker, 1993; Ellwood \& Kane, 2000), these findings suggest that sex differences in the benefits of higher education may be a source of the observed differences between women and men in college enrollment and degree attainment rates. The findings also suggest that observed racial/ethnic and SES group differences in college enrollment cannot be attributed to actual differences across these groups in the economic and non-economic benefits of higher education, as some benefits are greater for African Americans than for Whites and benefits generally do not vary by SES. However, the pattern of racial/ ethnic group differences in the relationship between educational attainment and non-economic benefits suggests that government efforts that are designed to reduce racial/ethnic group gaps in college enrollment and degree attainment are justified.

\section{The Benefits of Higher Education}

At least three types of challenges restrict attempts to measure the public and private benefits of higher education (Bowen, 1997; Institute for Higher Education Policy, 1998; Kane, 1999; McPherson \& Shapiro, 1997). First, the outcomes of higher education are diverse and can be complex, volatile, indirect, and interrelated (Bowen, 1997). Second, higher education is only one of many potential causes of any potential benefit. Among the other causes are elementary and secondary education, maturation, personal background characteristics, and other life experiences (Bowen, 1997; McPherson \& Shapiro, 1997). Third, the effects of higher education are not restricted to a specific outcome at one point in time but are generated and accumulated over the course of an individual's lifetime (Bowen, 1997; McPherson \& Shapiro, 1997).

Given these difficulties, as other researchers and policy analysts (Institute for Higher Education Policy, 1998; McPherson \& Shapiro, 1997) have observed, few have attempted to thoroughly measure the range of public and private, economic and non-economic benefits of higher education since William Bowen's Investment in Learning was first published in 1977. Bowen systematically describes what is known about the ways in which higher levels of educational attainment generate not only economic returns for an individual, but also non-economic benefits in the realms of cognitive learning, emotional and moral development, citizenship, family life, consumer 
behavior, leisure, and health for an individual and benefits in terms of neighborhood effects and growth in the national economy for society.

Several recent reports suggest efforts to increase attention to the public and private benefits of higher education. The National Center for Public Policy and Higher Education (2002) includes "benefits" as one of the six categories on which each state is graded in its Measuring Up report cards. Among the indicators of benefits are educational attainment of the population, percentage of personal income that is associated with bachelor's degree attainment, voting rates, charitable giving, and adult literacy. In their descriptive report of the status of 1988 eighth graders in 2000, Steven J. Ingels and colleagues (2002) reported that levels of such indicators as job satisfaction, use of computers on the job, participation in job training, and volunteer work increased with educational attainment, while the percentage of individuals receiving welfare and other forms of public assistance declined with educational attainment. In what may become a regular College Board publication, Sandy Baum and Kathleen Payea (2004) use descriptive analyses from several sources to describe the positive relationship between educational attainment and such benefits as earnings, unemployment, poverty rates, perceptions of health, smoking rates, incarceration rates, school readiness, volunteerism, voting, blood donations, and social programs.

These reports highlight a number of the benefits that result from higher education. Nonetheless, while the reports describe the relationship between various benefits and educational attainment, they generally do not examine the extent to which the relationship between educational attainment and benefits other than earnings varies across different groups.

\section{Theoretical Framework}

Some researchers have responded to the challenges that are associated with measuring benefits by focusing on one economic benefit of higher education: earnings (Kane, 1999; Leslie \& Brinkman, 1988; Perna, 2003). Most examinations of the benefits of higher education focus on average experiences across all individuals. Findings from the limited research (e.g., Geske \& Cohn, 1998; Perna, 2003) examining variations in earnings that are associated with higher education based on such individual characteristics as sex, race, and family income are equivocal. Using data from the longitudinal High School \& Beyond Survey of 1980 high school sophomores, I found that the relationship between educational attainment and salaries did not vary between men and women or among high school graduates of different racial/ethnic groups (Perna, 2003). In contrast, Samuel T. Cooper and Elchanah Cohn (1997) found, based on their analyses of data from the 1985 wave of the Panel Study of Income Dynamics, that the return to an 
investment in a college education was higher for women than for men after controlling for age, experience, marital status, geographic region, and membership in a union.

Researchers typically use human capital theory to guide examinations of the economic benefits of higher education. According to human capital theory, earnings and other labor market outcomes are determined by an individual's productivity, the investments an individual has made in his or her productivity, and the supply of and demand for workers with similar levels and types of training and expertise (Becker, 1962, 1993; Paulsen, 2001; Schultz, 1961). Differences in productivity are expected to be attributable to differences in the investments that individuals make in their personal development, such as the quantity and quality of their education, the amount of their on-the-job training, their geographic mobility, and their emotional and physical health (Becker, 1962; Schultz, 1961). Additional years of education are expected to raise productivity_and, hence—earnings, "mainly by providing knowledge, skills, and a way of analyzing problems" (Becker, 1993, p. 19).

Rational models of human capital investment assume that individuals decide to invest in additional education based on a comparison of the expected lifetime benefits with the expected costs (Becker, 1962, 1993; Ellwood \& Kane, 2000; Paulsen, 2001). This model assumes that individuals act rationally in ways that maximize their utility, given their personal preferences, tastes, and expectations (Becker, 1962, 1993). Human capital theory assumes that individuals consider both monetary and nonmonetary benefits in their calculation of the total expected benefits of higher education (Becker, 1993).

\section{Research Methods}

Using descriptive and multivariate analyses of data from the National Educational Longitudinal Study (NELS:92/20), this study examines how the benefits of higher education vary across sex, racial/ethnic, and SES groups. Whereas existing research quantifying the benefits of higher education focuses almost exclusively on a narrow set of economic benefits (i.e., earnings), this study also explores non-economic benefits, addressing two research questions:

1. What economic benefits did 1992 high school graduates who attained various levels of education realize by 2000 ? How do the economic benefits that are associated with various levels of educational attainment vary by sex, race/ethnicity, and SES?

2. What non-economic benefits did 1992 high school graduates who attained various levels of education realize by 2000 ? How do benefits that are associated with different levels of educational attainment vary by sex, race/ ethnicity, and SES? 


\section{Data and Sample}

Sponsored by the U.S. Department of Education, the NELS tracks the educational and occupational progress of a group of students beginning in 1988 , with follow-ups in 1990, 1992, 1994, and 2000. Because the focus of this research is on the effects of higher education rather than high school, the analytic sample is limited to students who were high school graduates in 1992 and who participated in the 1994 and 2000 follow-ups. The analytic sample is further restricted to cases with data for educational attainment in 2000. The total number of cases in the analytic sample is 9,773.

To correct for the oversampling of certain groups, nonresponse, and sampling error while minimizing the effects of large sample sizes on standard errors and tests of statistical significance, I applied the normalized panel weight (F4F2PNWT) to the data. I used AM statistical software, developed by the American Institutes for Research, to correct for the design effects that are associated with the nested nature of the data (i.e., students selected from selected schools). AM employs a Taylor-series approximation to calculate appropriate standard errors for complex samples such as the NELS (American Institutes for Research, 2004).

Descriptive analyses, including cross-tabulations and analysis of variance, identify observed differences in benefits by educational attainment, sex, race/ethnicity, and SES. I employ ordinary least squares regression to examine the relationship between educational attainment and the continuous dependent variable, income in 1999, after controlling for other variables. Using logistic regression, I examine the relationship between educational attainment and other selected measures of economic and noneconomic benefits (all dichotomous variables), holding constant other variables. Interaction terms between educational attainment and sex, race/ ethnicity, and SES test for variations in the relationships across groups. To facilitate the interpretation of the logistic regression coefficients, I use the delta- $p$ statistic to estimate the change in the probability of an outcome occurring that is associated with a one-unit change in a given independent variable (Cabrera, 1994; Petersen, 1985).

\section{Variables}

The benefits of higher education may be classified along various dimensions, including direct versus indirect, consumption versus investment, monetary versus nonmonetary, and public versus private (Geske \& Cohn, 1998; Institute for Higher Education Policy, 1998). This study categorizes benefits as either economic or non-economic. Following the suggestion of the Institute for Higher Education Policy (1998), economic benefits describe economic, fiscal, and labor advantages. Specifically, economic benefits are 
measured by annual income in 1999, fringe benefits (i.e., health insurance coverage, yes/no), and receipt of any type of public assistance in 1999 (yes/ no).

Working conditions, an aspect of labor advantages, are measured by job satisfaction and perceived employment-related benefits. Although the NELS:92/00 dataset includes measures that reflect satisfaction (yes/no) with eight aspects of employment (fringe benefits, further training, promotion opportunities, use of past training, work importance, pay, job security, and overall), these exploratory analyses are based on the indicator of overall job satisfaction. Perceived employment-related benefits reflect whether individuals perceived that postsecondary attendance resulted (yes/no) in all five of the following benefits: better jobs, higher salary, more responsibility, promotion opportunity, and improved job performance.

Non-economic benefits measure aspects of health-related behaviors (i.e., participate in fitness activities each day; drink alcoholic beverages; engage in binge drinking; smoke cigarettes), leisure activities (i.e., read books daily and attend plays or concerts at least twice each month), and civic involvement (i.e., vote in presidential and other elections and volunteer in a civic or community organization).

The primary independent variable, educational attainment, reflects the highest level of education that a student completed by 2000: no postsecondary education, some postsecondary education, certificate or license, associate's degree, bachelor's degree, or advanced degree. The analyses also include variables that control for sex, race/ethnicity, SES, and academic achievement. I consider these effects for five racial/ethnic groups: American Indian, Asian, Black, Hispanic, and White. SES in 1992 is measured by the $z$-scored, continuous NELS-derived composite that is based on mother's and father's educational attainment, mother's and father's occupation, family income, and the number of selected items in the home (e.g., daily newspaper, computer, atlas, more than 50 books).

Human capital theory recognizes that the observed relationship between various benefits and educational attainment may be caused by variables other than college attendance, such as an individual's ability and motivation (Becker, 1993). In other words, individuals who attained a bachelor's degree may have higher earnings in part because they have greater academic ability and higher levels of motivation than individuals who attain only a high school diploma. Because of their higher levels of ability and motivation, the economic and non-economic outcomes of these individuals would likely be higher than the outcomes of individuals who attained only a high school degree regardless of the actual level of education attained. This study measures achievement by the standardized composite test score on the NELS 1992 reading and mathematics tests. 


\section{FINDINGS}

\section{Economic Benefits of Higher Education}

Income. Descriptive analyses show that income varies by educational attainment. Table 1 suggests that about $88 \%$ of 1992 high school graduates who attained a bachelor's degree had some amount of income in 1999, compared with $84 \%$ of 1992 high school graduates with no postsecondary education. Among high school graduates with income, average incomes were substantially higher for individuals who attained a bachelor's degree $(\$ 30,570)$ than for individuals with no postsecondary education $(\$ 25,237)$, some postsecondary education $(\$ 24,611)$, a certificate or license $(\$ 23,707)$, or an associate's degree $(\$ 26,130)$. OLS regression analyses show that, before adding interactions but after controlling for sex, race/ethnicity, SES, and test scores, average incomes in 1999 were 19\% higher for high school graduates who attained a bachelor's degree than for high school graduates with no postsecondary education (Table 2 , model 1 ).

Two-way ANOVA shows that average incomes vary by sex, race/ethnicity, and SES, and that the effects of both sex and SES on income vary by educational attainment (Table 1). The gap between the average incomes of high school and college graduates was larger for women than for men. Among women, average salaries of college graduates were $55 \%$ higher than the average salaries of high school graduates; among men, the premium was $17 \%$. The college earnings premium was smaller among individuals in the second quartile of SES than among other students (5\% versus $21 \%$ overall) but was comparable across racial/ethnic groups.

The test of interactions in the regression analyses also shows differences between women and men in the relationship between educational attainment and income. Table 2, model 2, shows that the relationship between educational attainment and earnings varies by sex but not by race/ethnicity or SES. Although men who attained an associate's, bachelor's, or advanced degree average incomes that were comparable to incomes of men with no postsecondary education (net of other variables), women who attained an associate's, bachelor's, or advanced degree average incomes that were $32 \%$, $45 \%$, and $81 \%$ higher, respectively, than women with no postsecondary education.

Health insurance coverage. Table 3 shows that the share of 1992 high school graduates who were covered by health insurance increased with educational attainment, ranging from $79 \%$ of those with no postsecondary education to $92 \%$ of those who attained at least a bachelor's degree. Logistic regression analyses (Table 4) show that, even after controlling for sex, race/ethnicity, SES, test scores, and interactions, high school graduates who attained a certificate or a bachelor's degree were more likely than high school graduates with no postsecondary education to have health insurance coverage. 


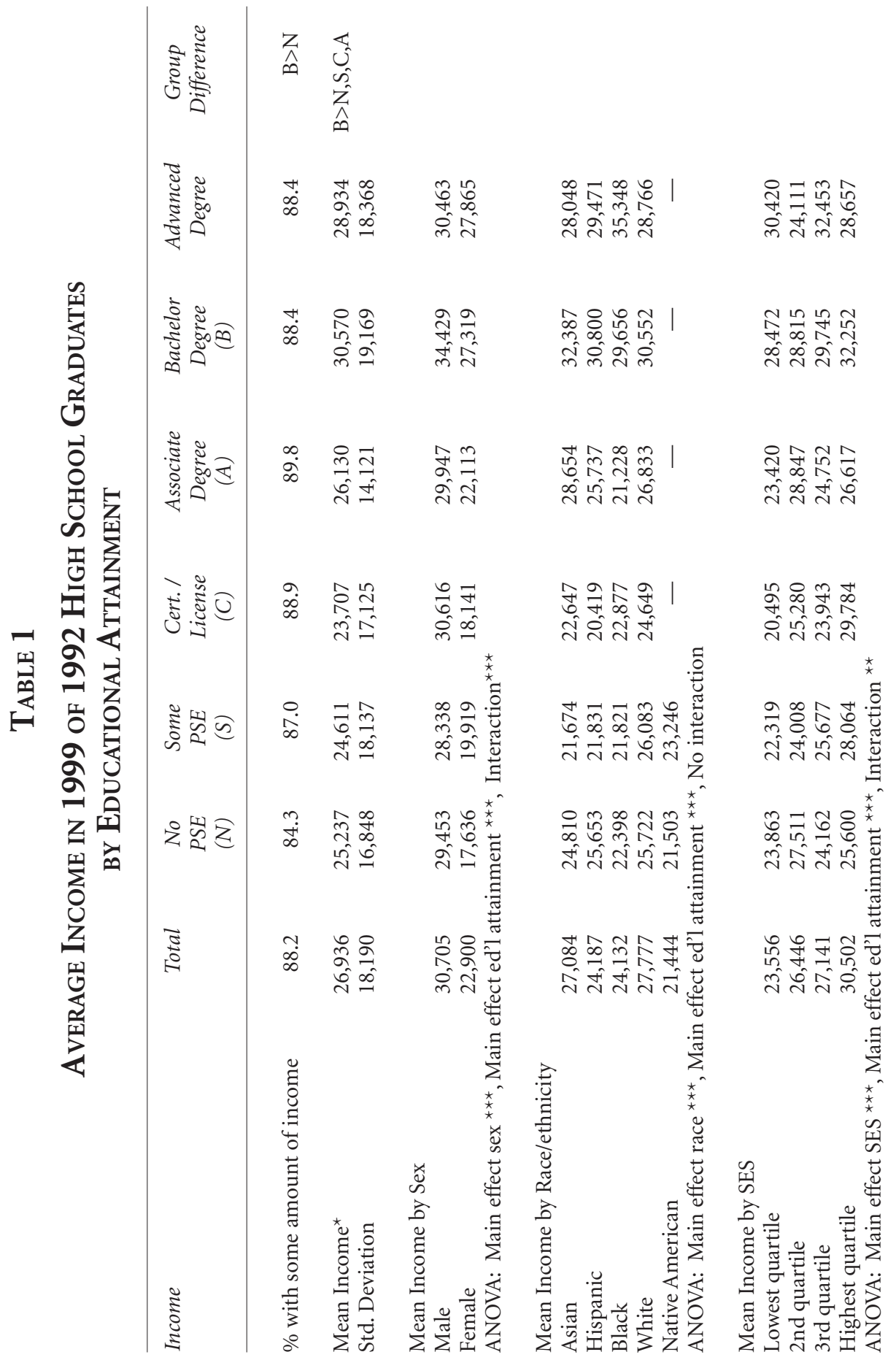


Table 1, cont.

Source: Analyses of NELS:92/00

${ }^{*}$ Mean income is calculated only for high school graduates with some amount of income.

— Indicates that sample size is too small to estimate.

Notes: Data are weighted by normalized panel weight (F4F2PNWT) and adjusted for strata and cluster effects. Group difference column represents comparisons between bachelor's degree and lower attainment categories, $p<.05$ with Bonferroni correction, calculated with AM Statistical Software.

\section{TABLE 2}

\section{Predictors of 1999 Income (Natural Log) Among 1992 High School Graduates}

\begin{tabular}{|c|c|c|c|c|}
\hline \multirow[b]{2}{*}{ Variable } & \multicolumn{2}{|c|}{$\begin{array}{c}\text { Model } 1 \\
\text { Highest Degree }\end{array}$} & \multicolumn{2}{|c|}{$\begin{array}{c}\text { Model } 2 \\
+ \text { Interactions }\end{array}$} \\
\hline & $B$ & Std. Error & $B$ & Std. Error \\
\hline $\begin{array}{l}\text { Female } \\
\text { (Male) }\end{array}$ & -0.33 & $0.03^{* * *}$ & -0.63 & $0.06^{* * *}$ \\
\hline American Indian & -0.16 & 0.12 & -0.15 & 0.12 \\
\hline Asian & -0.12 & 0.08 & -0.10 & 0.08 \\
\hline Black & 0.00 & 0.05 & -0.01 & 0.04 \\
\hline $\begin{array}{l}\text { Hispanic } \\
\text { (White) }\end{array}$ & -0.03 & 0.04 & -0.01 & 0.04 \\
\hline SES, z-score & 0.02 & 0.01 & 0.02 & 0.01 \\
\hline $\begin{array}{l}\text { Test score, z-score } \\
\text { (No PSE) }\end{array}$ & 0.02 & 0.02 & 0.02 & 0.02 \\
\hline Some PSE & -0.03 & 0.04 & -0.13 & $0.05^{\star *}$ \\
\hline Certificate & -0.09 & 0.07 & -0.03 & 0.07 \\
\hline Associate & 0.04 & 0.04 & -0.08 & 0.05 \\
\hline Bachelor & 0.19 & $0.04^{* * *}$ & 0.00 & 0.05 \\
\hline Advanced & 0.05 & 0.12 & -0.36 & 0.23 \\
\hline Some college $\mathrm{x}$ female & & & 0.27 & $0.08^{* * *}$ \\
\hline Associate's x female & & & 0.32 & $0.09^{* * *}$ \\
\hline Bachelor x female & & & 0.45 & $0.07^{* * *}$ \\
\hline Advanced $\mathrm{x}$ female & & & 0.81 & $0.25^{\star *}$ \\
\hline Constant & 10.10 & $0.03^{* * *}$ & 10.21 & $0.04^{* * *}$ \\
\hline Number cases & & 6,989 & & \\
\hline $\mathrm{R}^{2}$ & & 0.07 & & 0.09 \\
\hline \multicolumn{5}{|c|}{$\begin{array}{l}\text { Source: Analyses of NELS: } 92 / 00 \\
\text { Notes: Data are weighted by normalized panel weight (F4F2PNWT) and adjusted for strata and cluster } \\
\text { using AM Statistical Software. } \\
{ }^{* *} \mathrm{p}<.001,{ }^{* *} \mathrm{p}<.01,{ }^{\star} \mathrm{p}<.05\end{array}$} \\
\hline
\end{tabular}


But the statistically significant interactions in Table 4 suggest that the relationship between educational attainment and the likelihood of having health insurance coverage varies by sex and race/ethnicity. Relative to attaining no postsecondary education, the increase in the likelihood of having health insurance was higher for women than for men who attained some postsecondary education, an associate's degree, a bachelor's degree, or an advanced degree. Descriptive analyses (Table 3 ) suggest that the higher health insurance "premium" for women than for men is largely attributable to the low rates of health insurance coverage among women with no postsecondary education. Only $73 \%$ of women, but $84 \%$ of men, with no postsecondary education had health insurance.

The logistic regression analyses in Table 4 also show that, although high school graduates who attained some postsecondary education were generally as likely as those with no postsecondary education to have health insurance, Blacks who attained some postsecondary education were 7 percentage points more likely to have health insurance coverage than Blacks with no postsecondary education. Descriptive analyses (Table 3 ) suggest that the greater health insurance premium for some postsecondary education for Blacks than for Whites is attributable both to the relatively low rate of health insurance for Blacks with no postsecondary education (71\% versus $82 \%)$ and the relatively high rate of health insurance for Blacks with some postsecondary education ( $86 \%$ versus $81 \%$ ).

Public assistance. Virtually no high school graduates who attained an associate's degree $(0.6 \%)$, a bachelor's degree $(0.3 \%)$, or advanced degree $(0.3 \%)$ received public assistance (e.g., food stamps, welfare, housing assistance, etc.) in 1999, compared with $4 \%$ of high school graduates who completed no postsecondary education and 3\% of high school graduates who completed only some postsecondary education (Table 3).

Table 4 shows that, even after controlling for sex, race, SES, and test scores, high school graduates who attained an associate's degree were 1 percentage point less likely, and high school graduates who attained a bachelor's degree were 2 percentage points less likely, than high school graduates with no postsecondary education to receive public assistance. The absence of statistically significant interactions suggests that the relationship between educational attainment and the likelihood of receiving public assistance did not vary by sex, race/ethnicity, or SES. Nonetheless, the small number of cases receiving public assistance may limit the ability of the analyses to detect statistically significant differences. Descriptive analyses (Table 3) suggest that increased educational attainment has a larger effect on the likelihood of receiving public assistance for women than for men. Less than $0.5 \%$ of both women and men who attained a bachelor's degree received public assistance, while a substantially higher share of women than men 


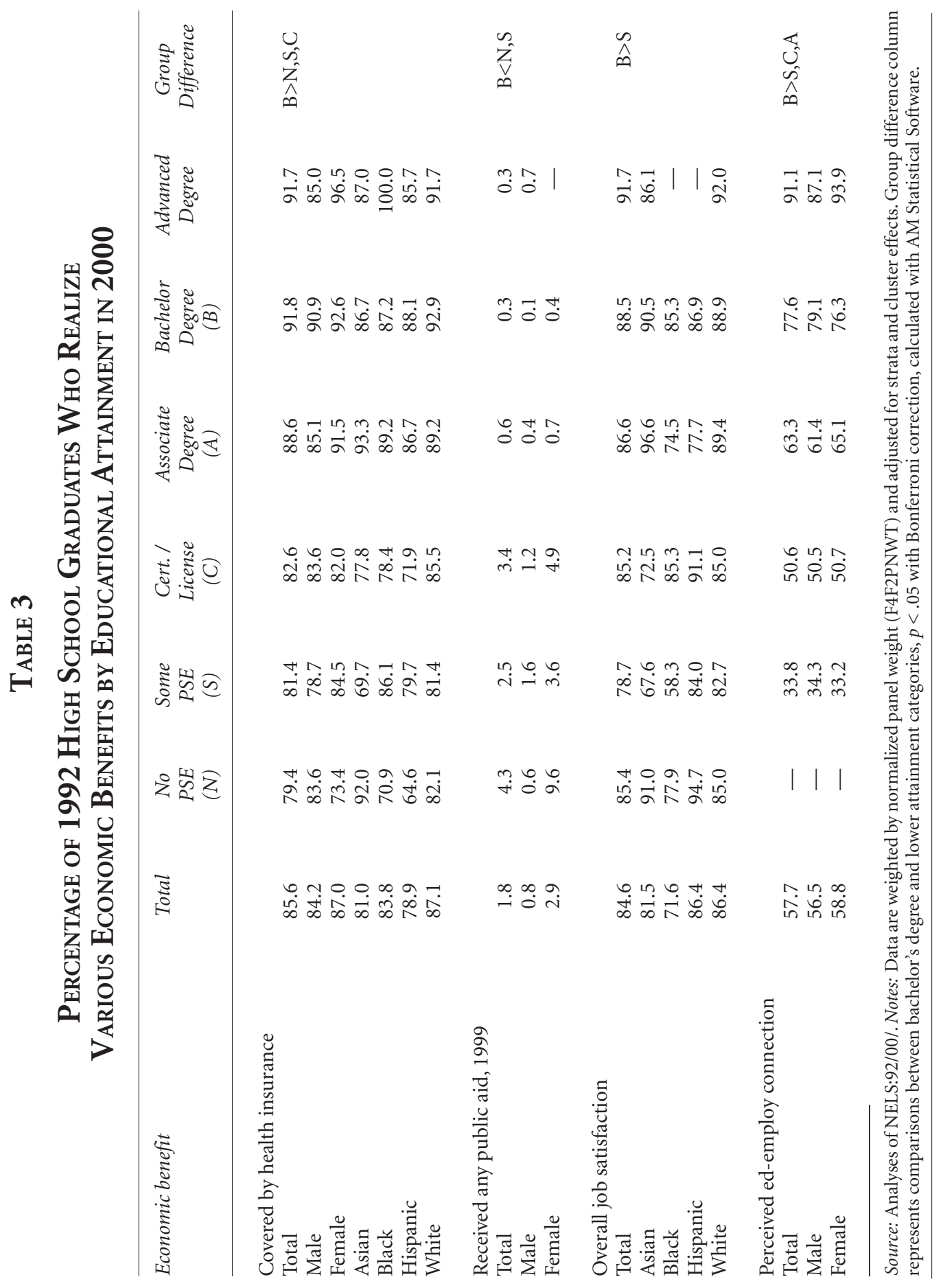




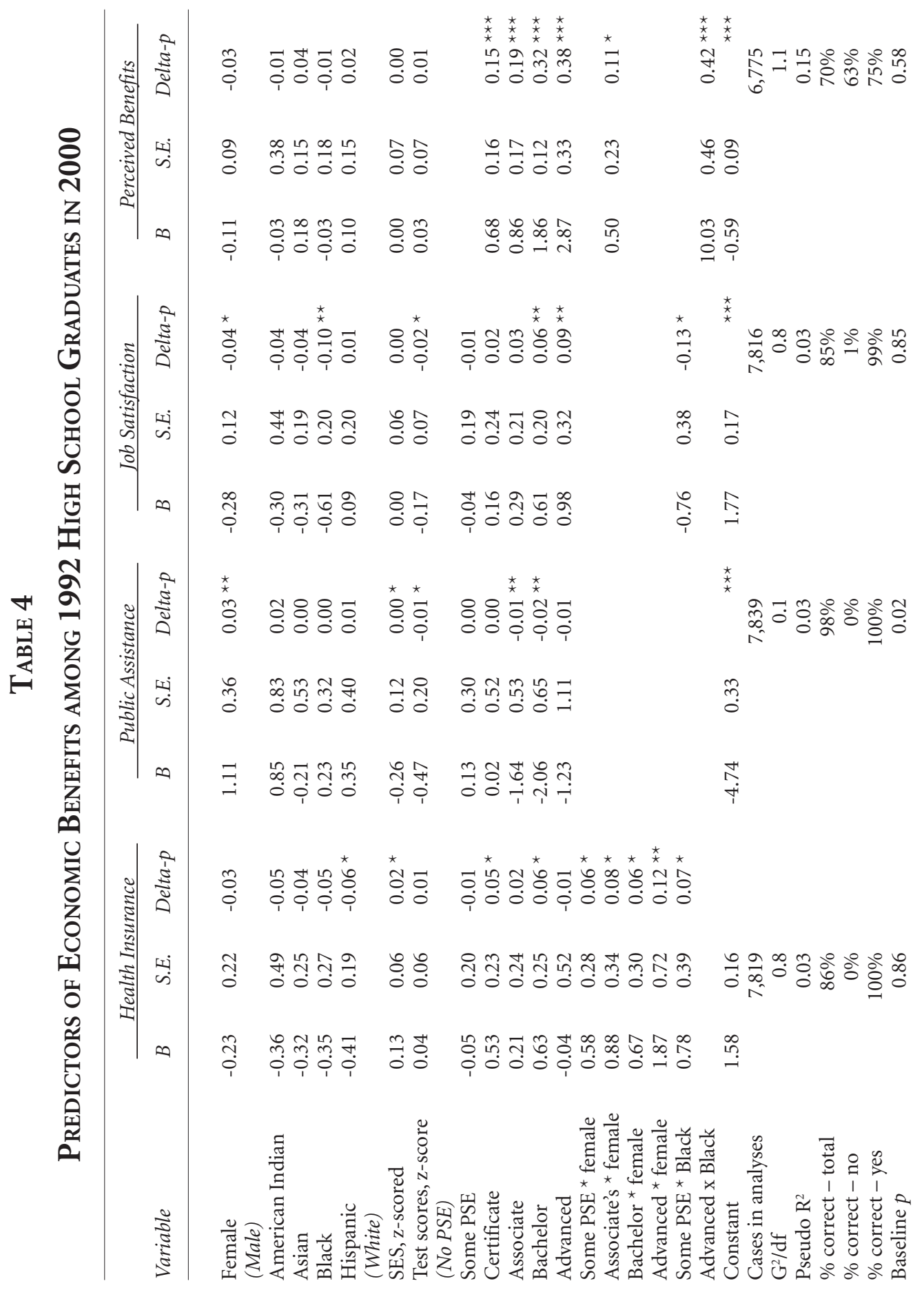


Table 4, cont.

\section{Source: Analyses of NELS:92/00}

Notes: The delta- $p$ statistic represents the change in the probability of an outcome occurring that is associated with a one-unit change in each independent variable (Cabrera, 1994). Delta- $p=\exp \left(\mathrm{L}_{1}\right) /[1$ $\left.+\exp \left(\mathrm{L}_{1}\right)\right]-\mathrm{P}_{0} \quad$ Pseudo $\mathrm{R}^{2}=\mathrm{c}^{2} /\left(\mathrm{N}+\mathrm{c}^{2}\right)$

Reference group for educational attainment in perceived benefits analysis is some PSE.

Coefficients calculated using AM. Goodness of fit statistics obtained using SPSS. ${ }^{* * *} \mathrm{p}<.001,{ }^{* *} \mathrm{p}<.01$, ${ }^{\star} \mathrm{p}<.05$

who attained no postsecondary education received public assistance (9.6\% of women versus $0.6 \%$ of men).

Job satisfaction. In terms of working conditions, high school graduates who attained a bachelor's degree generally appear to be more satisfied with their jobs than high school graduates who completed only some postsecondary education. Table 3 shows that about $79 \%$ of those with some postsecondary education are satisfied with their jobs, compared with $89 \%$ of those who attained a bachelor's degree. Table 4 shows that, after controlling for sex, race/ethnicity, SES, and test scores, high school graduates who attained a bachelor's degree (delta- $p=0.6$ ) or an advanced degree (delta- $p$ $=0.09$ ) were more likely than high school graduates with no postsecondary education to be satisfied with their jobs.

The statistically significant interaction in Table 4 suggests that the relationship between job satisfaction and educational attainment is different for Blacks than Whites. Although high school graduates who attained some postsecondary education are generally as likely as those with no postsecondary education to be satisfied with their jobs, Blacks who attained some postsecondary education were 13 percentage points less likely than Blacks with no postsecondary education to be satisfied with their jobs. Descriptive analyses confirm this relationship. Although job satisfaction rates are lower for those who attained some postsecondary education than for those who attained no education beyond high school regardless of race/ ethnicity, the gap is larger for Blacks than for individuals of other groups. Only $58 \%$ of Blacks who attained some postsecondary education, but $78 \%$ of Blacks who attained no postsecondary education, reported being satisfied with their jobs.

Perceived benefits. Regardless of the level attained, high school graduates who participated in some form or amount of postsecondary education generally agreed that such participation resulted in the following five employment-related benefits: better jobs, higher salary, more responsibility, opportunities for promotion, and improved job performance. The percentage of high school graduates who perceived higher education as a cause of 
the five benefits was higher among those with bachelor's degrees than among those with lower levels of education. For example, one-third (34\%) of high school graduates who attained only some postsecondary education, but $78 \%$ of high school graduates who attained a bachelor's degree, perceived that their educational attainment contributed to all five of these benefits.

Table 4 shows that this positive relationship persists even after controlling for sex, race/ethnicity, SES, and test scores. A review of the delta- $p$ coefficients suggests that the likelihood of perceiving a positive connection between education and employment outcomes increased with the level of education attained. Compared to high school graduates with only some postsecondary education, high school graduates who attained a bachelor's degree were 32 percentage points more likely to perceive that all five benefits were related to higher education.

Table 4 also suggests that the relationship between educational attainment and the probability of perceiving a connection between educational attainment and employment-related benefits is different for women than for men and different for Blacks than for Whites. Specifically, the probability of perceiving a connection between educational attainment and the five employment-related benefits was higher for women than for men who attained an associate's degree rather than some postsecondary education. Descriptive analyses (Table 3 ) show that, while comparable shares of women and men who have attained some postsecondary education perceive all five benefits to be associated with higher education (34\%), a slightly higher share of women than men who attained an associate's degree perceive this connection (65\% versus $61 \%)$. With regard to racial/ethnic group differences, the statistically significant interaction in the logistic regression analysis (Table 4) suggests that perceived connection between higher education and employment-related benefits is greater for Blacks who attained an advanced degree rather than some postsecondary education than for their White counterparts.

\section{Non-economic Benefits of Higher Education}

Health-Related Behaviors. Despite an expectation that educational attainment would be positively related to health-related indicators (e.g., Bowen, 1997; Institute for Higher Education Policy, 1998; Rowley \& Hurtado, 2003), descriptive analyses suggest a mixed relationship between educational attainment and health-related behaviors among 1992 high school graduates in 2000. Contrary to expectations, a higher percentage of high school graduates with no postsecondary education (15\%) than of high school graduates with a bachelor's degree (8\%) report daily physical fitness activities. Also contrary to expectations, the percentage of high school graduates who reported that they consume alcoholic beverages increases with educational attainment, rising from $56 \%$ of high school graduates with no postsecondary 
education to $76 \%$ of high school graduates who attained a bachelor's degree. The frequency of binge drinking (consuming five or more drinks in one sitting) is unrelated to educational attainment.

In contrast, Table 5 shows that the percentage of high school graduates who reported smoking cigarettes declined as the level of educational attainment increased, falling from $32 \%$ of those with no postsecondary education to only $12 \%$ of those with a bachelor's degree. Logistic regression analyses show that this negative relationship persists even after controlling for sex, race, SES, and test scores. Table 6 shows that high school graduates who attained an associate's, bachelor's, or advanced degree are 9, 14, and 15 percentage points, respectively, less likely than their counterparts with no postsecondary education to smoke.

As indicated by the statistically significant interactions, Table 6 shows that the smoking "premium" that is associated with attaining some postsecondary education or an advanced degree is greater for women than for men. Descriptive analyses (Table 5) also illustrate this relationship, showing that smoking rates are comparable among women and men who attained a bachelor's degree (about 12\%), but substantially lower for women than for men who attained some postsecondary education (23\% versus $29 \%$ ) or an advanced degree ( $4 \%$ versus $12 \%$ ).

Leisure Activities. Descriptive analyses (Table 5) also suggest that educational attainment is positively related to some indicators of leisure activities. Compared with no postsecondary education, higher shares of high school graduates with a bachelor's degree report reading books daily (19\% versus $12 \%)$ and attending a play or concert at least twice a month $(29 \%$ versus $21 \%$ ). Regression analyses show that, even after controlling for sex, race/ethnicity, SES, and test scores, individuals who attained an associate's degree were 12 percentage points more likely than individuals who attained no postsecondary education beyond high school to attend at least two plays or concerts per month (Table 6).

The relationship between educational attainment and the likelihood of attending at least two plays or concerts per month varies by sex and socioeconomic status. Specifically, the statistically significant interactions in Table 6 suggest that women who attained some postsecondary education were less likely than women with no postsecondary education to attend plays or concerts, while men who attained some postsecondary education were as likely as men with no postsecondary education to attend plays or concerts. Attaining an associate's degree rather than no postsecondary education had a positive effect on the probability of attending plays or concerts for men but no effect for women. Mirroring this relationship, descriptive analyses (Table 5) show that, among men, the percentage who attended at least two plays or concerts per month is smaller for those with no postsecondary education (20\%) than for those who had some postsecondary education 


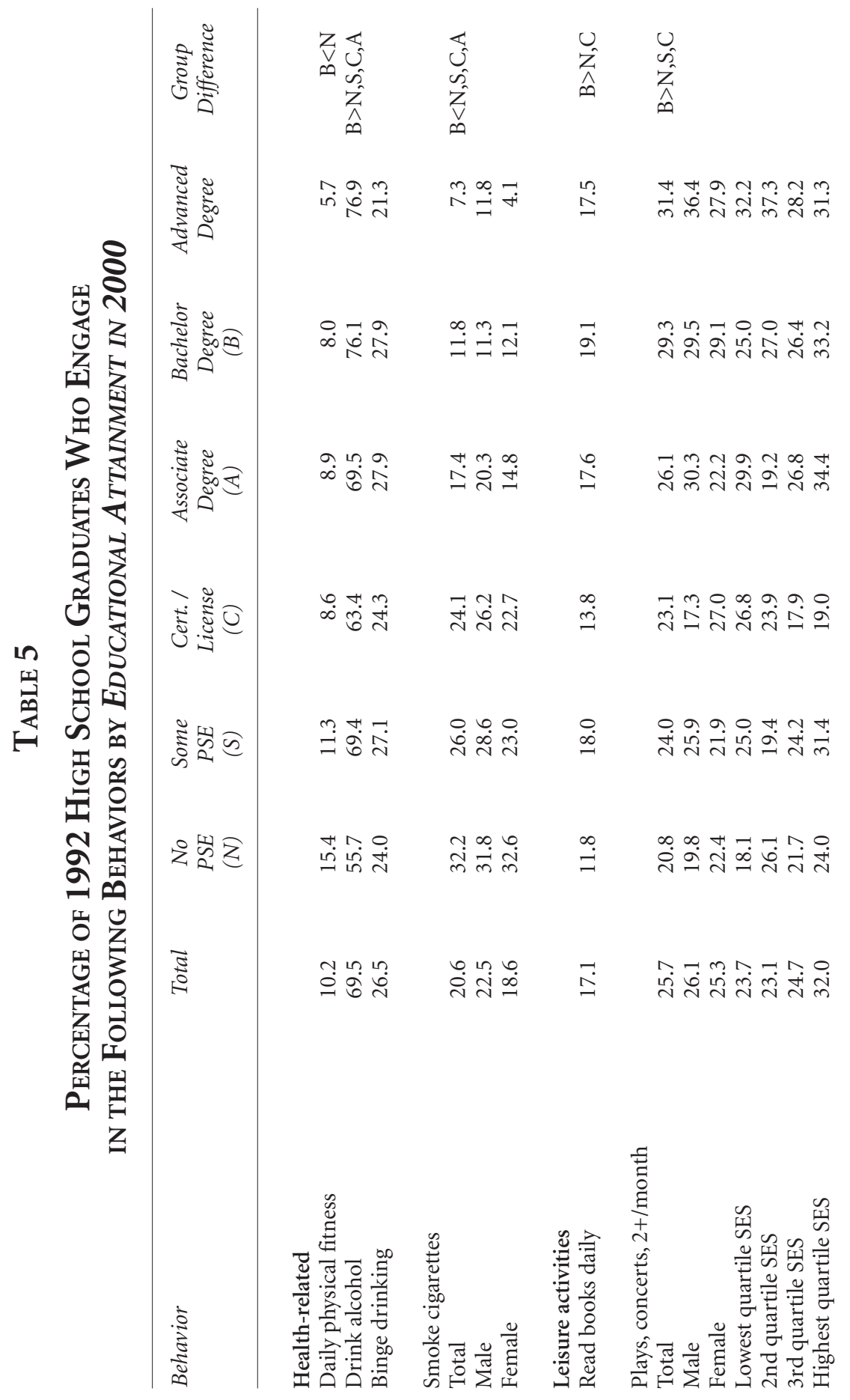




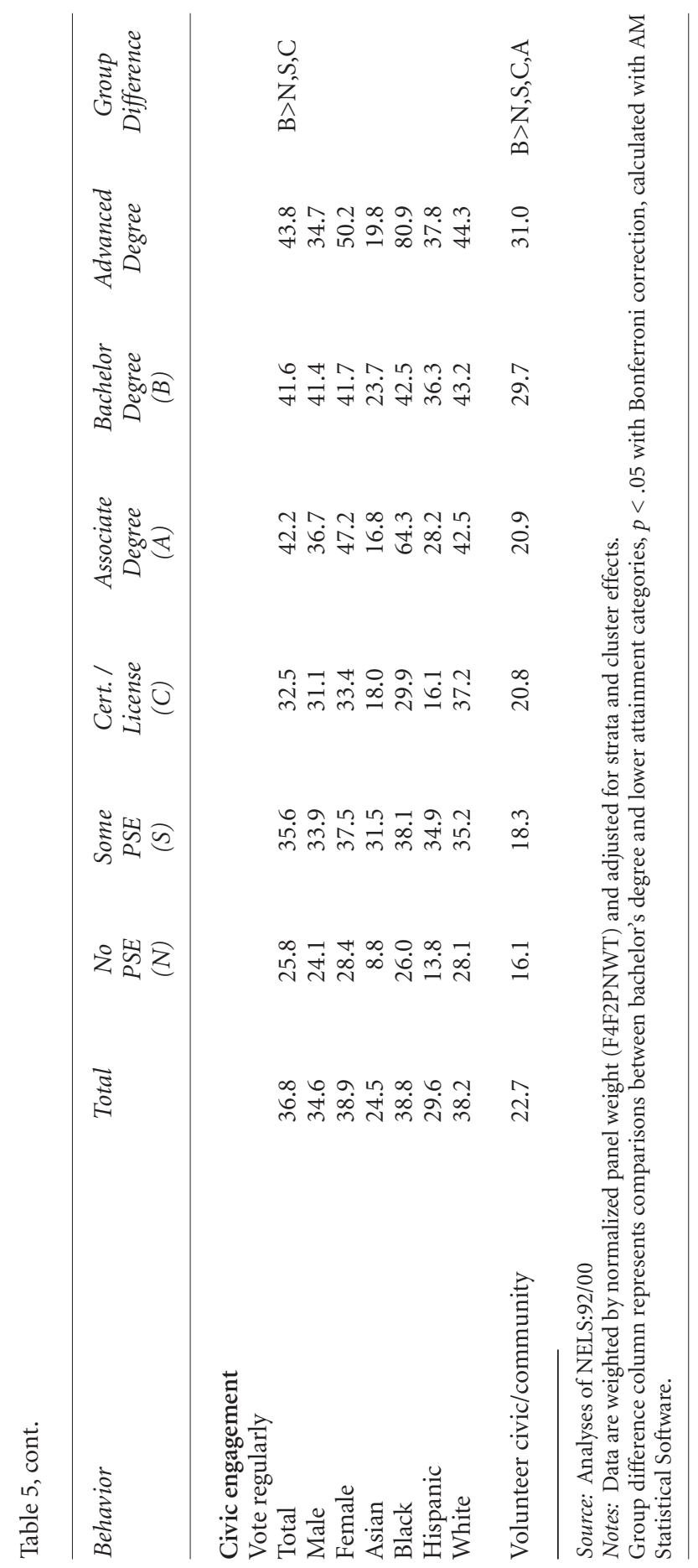




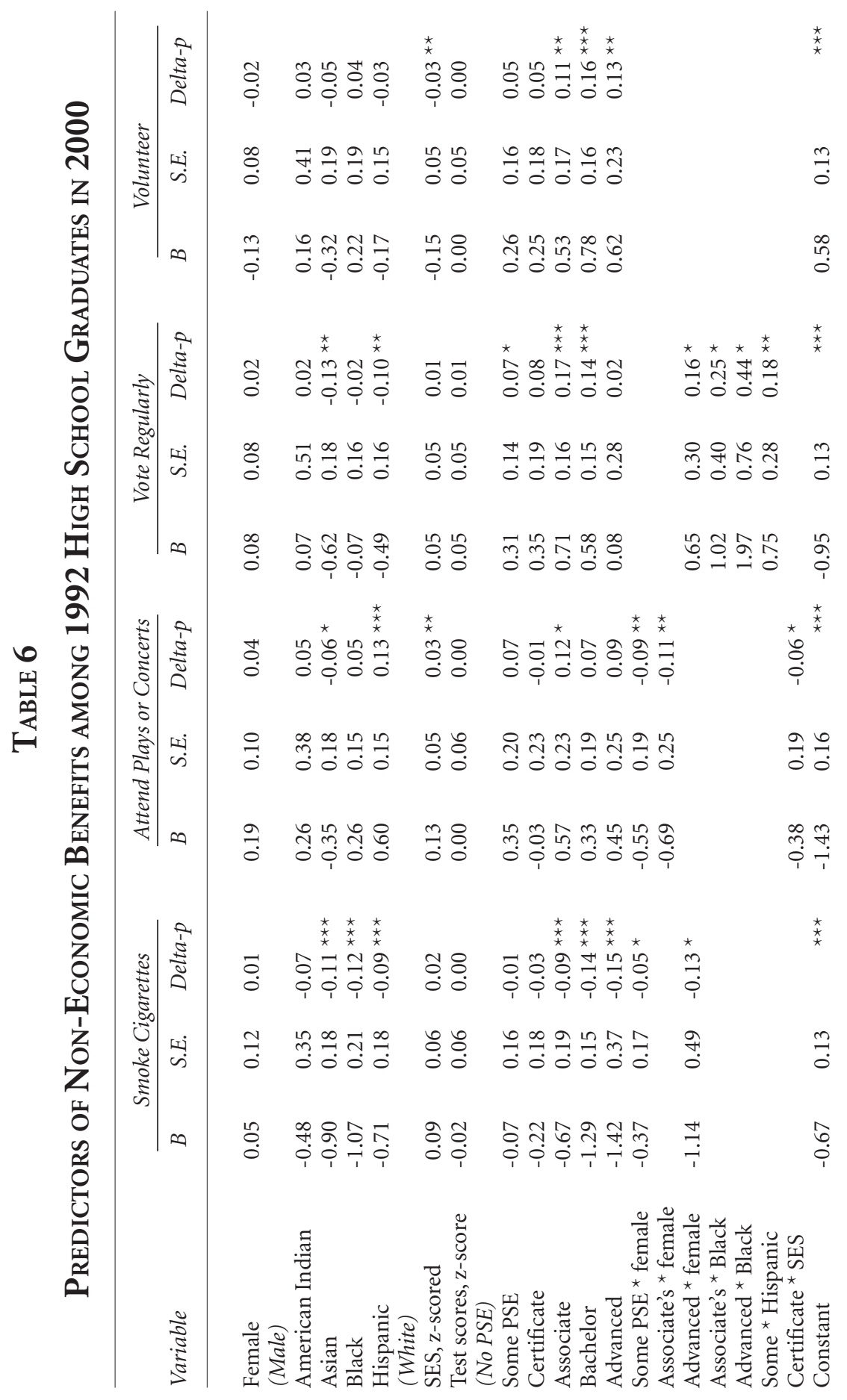




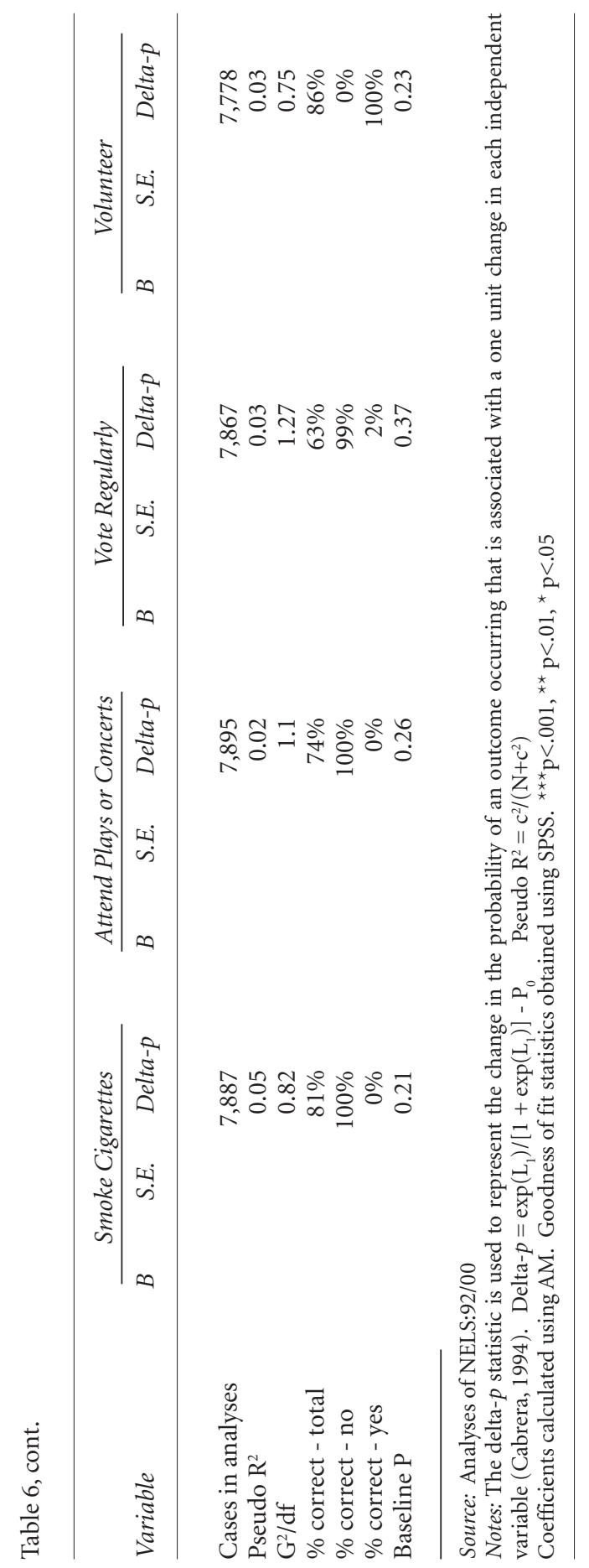


$(26 \%)$ or an associate's degree (30\%), while the percentage of women who attended at least two plays or concerts per month was comparable for those with no postsecondary education, some postsecondary education, or an associate's degree (22\%).

The analyses also suggest that, although the likelihood of attending two plays or concerts per month is generally comparable for individuals who attained a certificate and individuals who attained no education beyond high school, individuals with above-average SES who attained a certificate rather than no postsecondary education were less likely than their counterparts with lower SES to attend two plays or concerts each month. Further illustrating this relationship, descriptive analyses (Table 5) show that only $19 \%$ of individuals in the highest quartile of SES who attained a certificate attended at least two plays or concerts each month, compared with $27 \%$ of individuals in the lowest SES quartile who attained a certificate. In contrast, the share of high school graduates with no postsecondary education who regularly attended plays or concerts increased with SES (from 18\% of those with the lowest SES to $24 \%$ of those with the highest SES).

Civic Engagement. The analyses suggest that civic engagement is also positively related to educational attainment. Table 5 shows that only $26 \%$ of high school graduates with no postsecondary education voted in the 1996 presidential election and in other elections within a recent two-year period, compared with $42 \%$ of high school graduates who completed a bachelor's degree. Even after controlling for sex, race/ethnicity, SES, and test scores, high school graduates who attained some college (delta- $p=0.07)$, an associate's degree (delta- $p=0.17)$, or a bachelor's degree (delta- $p=0.14$ ) were more likely to vote regularly than high school graduates with no postsecondary education (Table 6).

A review of the statistically significant interactions suggests that the voting "premium" that is associated with educational attainment varies by sex and race/ethnicity. Unlike men, women who attained an advanced degree were more likely than women who attained no postsecondary education to vote regularly (delta- $p=0.16$ ). Descriptive analyses confirm this relationship, as Table 5 shows that, while only a slightly higher share of women than men with no education beyond high school voted regularly ( $28 \%$ versus $24 \%$ ), a substantially higher percentage of women than men who had attained an advanced degree voted regularly (50\% of women versus $35 \%$ of men).

Table 6 also suggests that the positive effects on voting regularly were higher among Blacks with associate's degrees (delta- $p=0.25$ ) and Blacks with advanced degrees (delta- $p=0.44$ ) than among Whites with comparable levels of educational attainment. While Hispanics were less likely, on average, than Whites to vote regularly (delta- $p=-0.10$ ), the "premium" in 
voting that was associated with attaining some postsecondary education rather than no education beyond high school was greater for Hispanics than for Whites. Illustrating this relationship, descriptive analyses show that a substantially smaller share of Hispanics than Whites with no postsecondary education voted regularly (14\% versus $28 \%$ ), but comparable shares of Hispanics and Whites with some postsecondary education (35\%) regularly voted.

Rates of volunteering in a civic or community organization also increase with educational attainment. Only $16 \%$ of those who completed no education beyond high school volunteered in a civic or community organization, compared with about $30 \%$ of those who attained a bachelor's degree (Table 6). Logistic regression analyses (Table 7) show that, after controlling for other variables, high school graduates who attained an associate's, bachelor's, or advanced degree are respectively 11,16 , and 13 percentage points more likely to volunteer in a civic or community organization than high school graduates with no postsecondary education. None of the interactions was statistically significant, suggesting that the relationship between volunteering and educational attainment did not vary by sex, race/ethnicity, or SES.

\section{Discussion}

This study sheds light on the economic and non-economic benefits that are associated with various levels of educational attainment among 1992 high school graduates eight years after graduating from high school, and the extent to which these benefits vary by sex, race/ethnicity, and SES. At least four conclusions may be drawn from this research.

First, as argued by human capital theorists (Becker, 1993) and demonstrated in prior descriptive reports (Baum \& Payea, 2004; Ingels et al., 2002; National Center for Public Policy and Higher Education, 2002), a variety of economic and non-economic benefits are associated with higher education. High school graduates who attained a bachelor's degree by 2000 appeared to benefit economically in terms of higher average incomes, greater likelihood of health insurance coverage, lower likelihood of receiving public assistance, greater job satisfaction, and greater perceived connection between higher education and employment-related benefits. Attaining a bachelor's degree rather than no postsecondary education was associated with greater non-economic benefits in the form of lower rates of smoking cigarettes, more frequent attendance at plays and concerts, and greater civic involvement as measured by both regular voting and volunteering in a civic or community organization.

Second, differences by sex in economic and non-economic "payoffs" of higher education suggest a potential explanation for higher rates of college enrollment and degree attainment for women than for men. The analyses 
suggest that the payoff to educational attainment is generally greater for women than for men in terms of such economic benefits as higher average incomes, greater likelihood of health insurance, lower likelihood of receiving public assistance, and greater perceived connection between higher education and employment-related benefits, and such non-economic benefits as a reduced likelihood of smoking and increased likelihood of regularly voting. The only variation in the benefits of educational attainment that favored men over women was regular attendance at plays and concerts. The higher "premiums" for women than for men for particular levels of educational attainment suggest that the higher college enrollment and degree attainment rates for women than for men reflect rational decision-making processes about the relative costs and benefits of higher education. As described above, human capital investment models predict that individuals will invest in higher education when the economic and non-economic benefits of attending exceed the costs of not attending (Paulsen, 2001).

Although the analyses suggest that the "premium" that is associated with completing a bachelor's degree rather than lower levels of education is greater for women than for men, it is important to note sex differences in the average level of benefits that are realized by women and men. Women are observed to average lower salaries than men at each level of educational attainment (Table 1), and this gender difference persists even after controlling for educational attainment and other variables (Table 2). Compared to men, more women receive public assistance and fewer women report satisfaction with their jobs even after controlling for differences in other variables (Table 4). Thus, this study points to a greater relative payoff to postsecondary educational attainment for women than for men but not greater economic status for women than for men. Additional research is required to understand the reasons for a greater payoff (at least in the shortterm) to higher education for women than for men, including gender differences in the types of jobs that are available to individuals with different levels of educational attainment, as well as the ways in which gender differences change over time (i.e., at points in time more than eight years after graduating from high school).

Third, the racial/ethnic group and SES differences in the relationship between educational attainment and the benefits of higher education that this study examined suggest that observed differences by race/ethnicity and SES in college enrollment are not attributable to differences across groups in the actual benefits of postsecondary educational attainment. Only one of the interactions between educational attainment and SES was statistically significant (attending plays or concerts twice a month) and that relationship was negative-suggesting a greater payoff to certificate recipients with lower SES than certificate recipients with higher SES. The effect of some postsecondary education on three economic indicators was different 
for Blacks than for Whites: health insurance coverage, job satisfaction, and perceived employment benefits. The effects of earning an associate's or advanced degree on the likelihood of voting were also different for Blacks than for Whites. With the exception of job satisfaction, all of these relationships reflected greater "payoffs" to particular levels of postsecondary education for Blacks than for Whites, suggesting that enrollment rates should be higher for Blacks than Whites.

The absence of lower benefits for Blacks or Hispanics than for Whites, or students of lower SES than for students of higher SES, suggests that observed differences in college enrollment by race/ethnicity and SES are not attributable to differences in the expected benefits of higher education, one component of a rational human capital investment model (Ellwood \& Kane, 2000; Paulsen, 2001). One potential implication of this finding is that ra$\mathrm{cial} / \mathrm{ethnic}$ and socioeconomic group differences in enrollment are related not to differences in the demand for human capital but to differences in the supply of funds available to pay the costs of an investment in higher education, including parental wealth and availability of federal and state student financial aid (Ellwood \& Kane, 2000; Paulsen, 2001).

A second potential implication of this finding is that observed differences in enrollment reflect differences across groups in the perceived, not the actual, benefits of higher education. The findings from this study do not reveal the extent to which individuals of different groups accurately estimate the actual benefits of higher education. Although economists assume that people form expectations in the same manner, evaluating the same variables and employing the same information-processing rules, the basis for individual expectations has not been examined (Dominitz \& Manski, 1996; Manski, 1993). Based on his review of relevant research, Michael Paulsen (2001) concluded that, on average, students accurately estimate the future and foregone earnings that are associated with higher education. But the accuracy of estimates varies both within and across groups, with less accurate estimates for students from lower-income families than for other students (Paulsen, 2001). Jeff Dominitz and Charles Manski (1996) found that, even in a sample of high school and college students with aboveaverage parental education and family income, estimates of both expected starting salaries of college graduates and earnings distributions of college graduates varied substantially. Women also tended to overestimate the current median earnings of female college graduates (Dominitz \& Manski, 1996).

In his exploratory study of undergraduates at one university, Julian Betts (1996) found that, even after controlling for gender, race, grade point average, parents' education, and major field, students from lower-income families had significantly lower estimates of both the starting salaries of college graduates and the average salaries of college graduates between the ages of 
25 and 34 who were working full-time. Moreover, the accuracy of estimates was greater for college seniors than for college freshmen (Betts, 1996). These findings suggest that many students enter college poorly informed about the expected economic benefits of their investment and that the lower observed enrollment rates for students from low-income than high-income families (and for Blacks and Hispanics than Whites) may reflect, at least in part, inaccurate knowledge about the benefits of higher education. Additional research is required to understand differences across groups in the accuracy of expected economic and non-economic benefits of higher education.

A third potential implication of this finding is that rational human capital investment models are not sufficient for understanding differences across groups in the demand for higher education. Although more research is needed to understand the correlation between actual and perceived benefits among individuals of different groups-building, for example, on the exploratory work of Betts (1996) and Dominitz and Manski (1996)—the findings from this research support the conclusion by others (e.g., Ellwood \& Kane, 2000; Paulsen, 2001; Paulsen \& St. John, 2002; Perna, 2000; St. John \& Asker, 2001) that rational human capital investment models do not adequately explain racial/ethnic or SES differences in college enrollment. Recognizing this limitation, some (e.g., Paulsen, 2001; Paulsen \& St. John, 2002; Perna, 2000; St. John \& Asker, 2001) recommend incorporating concepts of cultural and social capital into traditional human capital investment models. While "cultural capital" refers to the system of factors derived from one's parents that defines an individual's class status (Bourdieu \& Passeron, 1977), social capital refers to social networks and the ways in which social networks and connections are sustained (Morrow, 1999). Such approaches assume that students' educational decisions are determined, at least in part, by their "habitus," or the system of values and beliefs that shapes an individual's views and interpretations (Paulsen, 2001; Paulsen \& St. John, 2002; St. John \& Asker, 2001). This approach assumes that the pattern of educational attainment is not universal but may vary across racial/ethnic and other groups (Paulsen \& St. John, 2002; St. John \& Asker, 2001).

Finally, differences in the relationship between race/ethnicity and several non-economic benefits based on educational attainment suggest an additional type of justification for government interventions that are designed to reduce racial/ethnic gaps in college enrollment and degree attainment rates. Government intervention in the higher education market is typically justified based on the "spillover" of benefits beyond participants to nonparticipants, the inability of participants to use their post-higher education level of human capital as collateral against which to borrow funds needed to pay educational costs, inequities in access to information about college, and a public commitment to equalizing opportunity across groups 
(Geske \& Cohn, 1998; Kane, 1999; Paulsen, 2001). But the results of this study suggest that government policies designed to increase the college enrollment of Blacks and Hispanics may also be justified because of the social payoffs of such an investment. Specifically, this study suggests a greater return to educational attainment for Blacks and Hispanics than for Whites in terms of an indicator of civic involvement, regular voting.

\section{Directions for Future Research}

In addition to the areas already mentioned, the results of this study suggest at least three other directions for future research. As described above, many challenges limit the quantification of the benefits of higher education. This study, like any attempt, is "imperfect and incomplete" (Institute for Higher Education Policy, 1998). The measures included in this study reflect benefits at one point in time and are limited to the proxies available in the NELS dataset. As the Institute for Higher Education Policy (1998) notes, each benefit identified here likely leads to a "cascade of benefits" ( $p$. 13) from higher education that are realized over the course of a lifetime (i.e., beyond the point measured in this study of eight years after high school graduation). In addition, the dataset lacks measures of such potential benefits as saving, asset management, personal and professional mobility, consumer behavior, life expectancy, family planning, and quality of life for one's children (Geske \& Cohn, 1998; Institute for Higher Education Policy, 1998; Rowley \& Hurtado, 2003). The NELS dataset also does not provide indicators of intergenerational benefits or the ways in which the children of 1992 high school graduates will benefit from their parents' educational attainment. Bowen (1997) argues that intergenerational benefits are the single most important benefit of higher education. Thus, additional research is required to more completely understand the ways in which a more complete set of economic and non-economic benefits of higher education vary across individuals of different groups over the course of a lifetime.

Second, while this study focused on identifying the gross benefits of higher education, future research should explore sex, racial/ethnic, and socioeconomic group differences in the net benefits of higher education. This study not only ignored the costs of higher education (e.g., tuition and fees, room and board, opportunity costs, etc.), but also assumed that neither the costs nor the availability of resources to pay the costs varied among individuals of different backgrounds. Perhaps because of the complexity of such an analysis, only a few researchers (e.g., Hansen \& Weisbrod, 1969) have systematically compared the public and private benefits with the costs of higher education. Nonetheless, a study of the differences in the net benefits of educational attainment across groups would likely further inform our under- 
standing of the causes of continued observed differences in college enrollment and degree attainment.

Third, this study did not examine variations in benefits across groups who complete at least a bachelor's degree. Future research should examine differences in the range of economic and non-economic benefits that accrue to individuals who attend different types of institutions and who pursue different academic majors. Based on his review of prior research, Ronald Ehrenberg (2004) concluded that, after controlling for selection bias, research generally shows that starting salaries are higher for individuals who attend the most selective colleges and universities than for other individuals. Little is known, however, about the extent to which these and other payoffs vary by sex, race/ethnicity, or SES.

Finally, researchers should pay greater attention to quantifying the public or societal benefits of higher education. Public discourse about the benefits of higher education now focuses almost exclusively on the private economic benefits of higher education (Institute for Higher Education Policy, 1998). The National Forum on Higher Education for the Public Good (2003) found, based on data from a telephone survey and focus groups, that, when asked to define the benefits of American higher education, respondents emphasized the economic returns that accrue to individuals. Study participants generally perceived no direct contribution of higher education to civic, public, or societal outcomes (National Forum on Higher Education for the Public Good, 2003).

Nonetheless, higher education produces other benefits that, although not typically quantified, "spill over" to society. Although some researchers (e.g., Bowen, 1997; Institute for Higher Education Policy, 1998) attempt to separate private from public benefits, the two categories overlap. Because of the overlap, this study did not differentiate between private and public economic and non-economic benefits. Private and public benefits are clearly related. For example, this study shows that smoking rates decline as educational attainment increases. While this relationship benefits individuals in terms of improved health, society also benefits from the reduced costs of providing health care to smokers.

Although beyond the scope of the current study, developing comprehensive and complete quantifications of the public benefits of higher education may be especially important for justifying continued government financial support for higher education. Inadequate attention to the range of benefits that result from higher education may be one cause of recent shifts in federal and state government policies toward higher education (Institute for Higher Education Policy, 1998, 2004). These shifts reflect policymakers' assumption that the primary benefit of higher education is increased earnings for individual participants. Among the public policy 
trends that reflect this assumption are the decline in the share of public higher education revenues funded by state governments and the increase in the share funded by families (through tuition), the shift from grants to loans in terms of the primary type of financial aid that is awarded to students, the growth in financial aid that is awarded based on "merit" rather than financial need, the enactment of the federal tuition tax credits, and the growth in state-sponsored prepaid tuition and college savings plan programs (Institute for Higher Education Policy, 2004; Thomas \& Perna, 2004). Perhaps by improving documentation of the public benefits of higher education and then educating policymakers and communicating with the public about the ways in which society benefits when public resources are allocated to higher education, these trends can be reversed (Institute for Higher Education Policy, 1998; National Forum on Higher Education for the Public Good, 2003).

\section{REFERENCES}

American Institutes for Research (2004). What is AM statistical software? Retrieved on January 15, 2004, from http://am.air.org.

Baum, S., \& Payea, K. (2004). Education pays 2004: The benefits of higher education for individuals and society. Washington, DC: College Board.

Becker, G. S. (1962). Investment in human capital: A theoretical analysis. Journal of Political Economy, 70 Suppl.(5), 9-49.

Becker, G. S. (1993). Human capital: A theoretical and empirical analysis with special reference to education (3rd ed.). Chicago: University of Chicago Press.

Betts, J. R. (1996). What do students know about wages? Evidence from a survey of undergraduates. Journal of Human Resources, 31(1), 27-56.

Bourdieu, P., \& Passeron, J. C. (1977). Reproduction in education, society, and culture. Beverly Hills, CA: Sage Publications.

Bowen, H. R. (1977, 1997). Investment in learning: The individual and social value of American higher education. Baltimore, MD: Johns Hopkins University Press.

Cabrera, A. F. (1994). Logistic regression analysis in higher education: An applied perspective. In J. C. Smart (Ed.), Higher Education: Handbook of Theory and Research (Vol. 10, pp. 225-256). New York: Agathon Press.

Cooper, S. T., \& Cohn, E. (1997). Internal rates of return to college education in the United States by sex and race. Journal of Education Finance, 23, 101-133.

Dominitz, J., \& Manski, C. F. (1996). Eliciting student expectations of the returns to schooling. Journal of Human Resources, 31(1), 1-25.

Ehrenberg, R. G. (2004). Econometric studies of higher education. Journal of Econometrics, 121, 19-37.

Ellwood, D. T., \& Kane, T. J. (2000). Who is getting a college education? Family background and the growing gaps in enrollment. In S. \& W. J. Danziger (Eds.), Securing the future: Investing in children from birth to college (pp. 283-324). New York: Russell Sage Foundation. 
Geske, T. G., \& Cohn, E. (1998). Why is a high school diploma no longer enough? The economic and social benefits of higher education. In R. Fossey and M. Bateman (Eds.), Condemning students to debt: College loans and public policy (pp. 19-26). New York: Teachers College Press.

Gladieux, L., \& Swail, W. S. (1999). Financial aid is not enough: Improving the odds for minority and low-income students. In J. E. King (Ed.), Financing a college education: How it works, how it?s changing (pp. 177-197). Phoenix, AZ: American Council on Education/Oryx Press.

Hansen, W. L., \& Weisbrod, B. A. (1969). Benefits, costs, and finance of public higher education. Chicago: Markham Publishing.

Heller, D. E. (1997). Student price response in higher education: An update to Leslie and Brinkman. Journal of Higher Education, 68(6), 624-659.

Heller, D. E. (1999). The effects of tuition and state financial aid on public college enrollment. Review of Higher Education, 23(1), 65-89.

Hossler, D., Braxton, J., \& Coopersmith, G. (1989). Understanding student college choice. In J. C. Smart (Ed.), Higher Education: Handbook of Theory and Research (Vol. 5, pp. 231-288). New York: Agathon Press.

Ingels, S. J., Curtin, T. R., Kaufman, P., Alt, M. N., \& Chen, X. (2002). Coming of age in the 1990s: The eighth-grade class of 198812 years later. Washington, DC: Office of Educational Research and Improvement. NCES 2002-321.

Institute for Higher Education Policy. (1998). Reaping the benefits: Defining the public and private value of going to college. Washington, DC: Author.

Institute for Higher Education Policy. (2004). Investing in America?s future: Why student aid pays off for society and individuals. Washington, DC: Author.

Kane, T. J. (1999). The price of admission: Rethinking how Americans pay for college. Washington, DC: Brookings Institution Press.

Leslie, L. L., \& Brinkman, P. T. (1988). The economic value of higher education. Phoenix, AZ: American Council on Education/Oryx Press.

Manski, C. F. (1993). Adolescent econometricians: How do youth infer the returns to schooling? In C. T. Clotfeller \& M. Rothschild (Eds.), Studies of supply and demand in higher education (pp.43-57). Chicago: University of Chicago Press.

McPherson, M., \& Shapiro, M. (1997). Introduction. In H. R. Bowen (Ed.), Investment in learning: The individual and social value of American higher education. Baltimore, MD: Johns Hopkins University Press.

Morrow, V. (1999). Conceptualising social capital in relation to the well-being of children and young people: A critical review. Sociological Review, 47(4), 744765.

National Center for Education Statistics. (2003). Digest of education statistics: 2002. Washington, DC: Author. NCES 2003-060.

National Center for Public Policy and Higher Education. (2002). Measuring up 2002. San Jose, CA: Author.

National Forum on Higher Education for the Public Good. (2003). Higher education for the public good: A report from the national leadership dialogues. Ann Arbor, MI: Author.

Paulsen, M. B. (2001). The economics of the public sector: The nature and role of public policy in the finance of higher education. In M. B. Paulsen \& J. C. 
Smart (Eds.), The finance of higher education: Theory, research, policy, and practice (pp. 95-132). New York: Agathon Press.

Paulsen, M. B., \& St. John, E. P. (2002). Social class and college costs: Examining the financial nexus between college choice and persistence. Journal of Higher Education, 73, 189-236.

Perna, L. W. (2000). Differences in the decision to attend college among African Americans, Hispanics, and Whites. Journal of Higher Education, 71(2), 117141.

Perna, L. W. (2003). The private benefits of higher education: An examination of the earnings premium. Research in Higher Education, 44, 451-472.

Petersen, T. (1985). A comment on presenting results from logit and probit models. American Sociological Review, 50(1), 130-131.

Rowley, L. L., \& Hurtado, S. (2003). Non-monetary benefits of undergraduate education. In D. R. Lewis \& J. Hearn (Eds.), The public research university: Serving the public good in new times (pp. 207-229). Lanham, MD: University Press of America.

Schultz, T. W. (1961). Investment in human capital. American Economic Review, 51(1), 1-17.

St. John, E. P. (2003). Refinancing the college dream: Access, equal opportunity, and justice for taxpayers. Baltimore, MD: Johns Hopkins University Press.

St. John, E. P., \& Asker, E. H. (2001). The role of finances in student choice: A review of theory and research. In M. B. Paulsen \& J. C. Smart (Eds.), The finance of higher education: Theory, research, policy, and practice (pp. 419-438). New York: Agathon Press.

Thomas, S. L., \& Perna, L. W. (2004). The opportunity agenda: A reexamination of postsecondary reward and opportunity. In J. C. Smart (Ed.), Higher Education: Handbook of theory and research (Vol. 19, pp. 43-84). Dordrecht, The Netherlands: Kluwer Academic Publishers. 